\title{
O turismo em Patrimônio da Penha (ES) e suas interfaces com o Parque Nacional do Caparaó
}

\author{
The tourism in Patrimônio da Penha (ES, Brazil) and interfaces \\ with Caparaó National Park
}

\author{
Victor Silveira Massini, Bruno Pereira Bedim, \\ Ricardo Eustáquio Fonseca-Filho
}

\begin{abstract}
RESUMO
Este artigo discute o contexto do turismo na comunidade denominada Patrimônio da Penha, localizada no entorno do Parque Nacional do Caparaó, especificamente no município de Divino de São Lourenço (ES), local que possui grande biodiversidade e com isso muitos atrativos naturais. Analisamse aspectos institucionais passando por suas estratégias de manejo e dados sobre o uso público. A partir do método etnográfico (Alberti, 1989), realiza-se um estudo de caso sobre o turismo na referida comunidade, ressaltando-se aspectos socioculturais constatados em pesquisas de campo, que demonstram o desenvolvimento turístico no distrito e as influências advindas da existência de uma unidade de conservação na região.
\end{abstract}

PALAVRAS-CHAVE: Ecoturismo de Base Comunitária; Parque Nacional do Caparaó; Divino de São Lourenço; Patrimônio da Penha (ES).

\section{ABSTRACT}

This article discusses the context of tourism in the community called Patrimônio da Penha, located in the vicinity of the Caparaó National Park, specifically in the municipality of Divino de São Lourenço (ES), a place that has great biodiversity and with that many natural attractions. It examines institutional aspects through their management strategies and data on public use. From the ethnographic method (Alberti, 1989), carried out a case study on tourism in that community, emphasizing sociocultural aspects observed in field surveys, which show the development of tourism in the district and the influences arising from the existence of a protected area in the region.

KEYWORDS: Community-Based Ecotourism; Caparaó National Park; Divino de São Lourenço; Patrimônio da Penha (ES, Brazil). 


\section{Introdução}

Patrimônio da Penha é um distrito do município de Divino de São Lourenço (ES), e está localizado na zona de amortecimento do Parque Nacional do Caparaó, coberto por mata atlântica e com recursos hídricos abundantes. Em certo sentido, a região do Caparaó é privilegiada por ainda possuir espaços naturais com sua biodiversidade preservada, sendo um lugar agradável e apto para se viajar e desfrutar de uma boa qualidade de vida, o que se configura exatamente em o que muitos turistas buscam hoje, um lugar que Ihes proporcione bem estar e tranquilidade.

O Parque Nacional do Caparaó (PNC) localiza-se na divisa dos Estados de Minas Gerais e do Espírito Santo, compreendendo uma área de 31.800 hectares e perímetro aproximado de 160 quilômetros. 30\% da área do Parque estão em território mineiro, ao passo que $70 \%$ do parque está circunscrito em território capixaba, nos municípios de Dores do Rio Preto, Ibitirama, lúna, Irupi e Divino de São Lourenço (Figura 1).

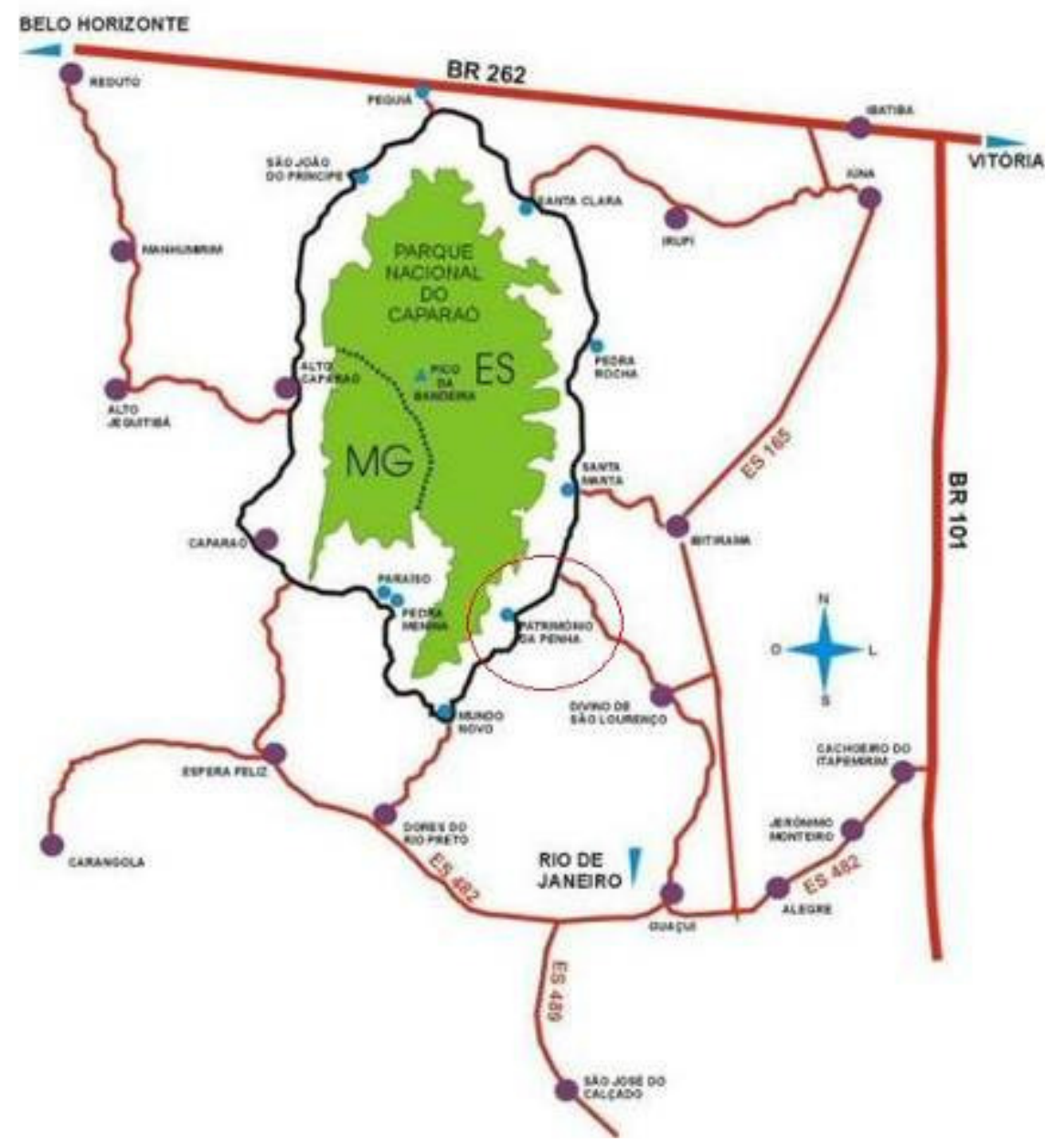

Figura 1: Mapa de localização e acesso. Fonte:

http://www.hospedagenssomdasaguas.com.br/ParqueNacional.aspx

Figure 1: Location Map and access. Source:

http://www.hospedagenssomdasaguas.com.br/ParqueNacional.aspx 
O Parque foi criado em 24 de maio de 1961 pelo decreto federal no 50.646 , tendo como justificativa "o fato de que, entre os lugares excepcionalmente dotados pela natureza exuberante, ocupa posição de destaque a Serra do Caparaó, ao lado do Pico da Bandeira, na divisa dos estados do Espírito Santo e Minas Gerais" (Ibama/MMA 1995). Além disso, a criação decorreu da importância ecológica da área que concentra distintas formações vegetais. A principal portaria de acesso ao parque foi durante muitos anos a que está situada no seu limite oeste, no município de Alto Caparaó (MG); atualmente o parque já conta com um outro ponto de acesso, pelo lado do Espírito Santo, a portaria nos limites ao sul do parque que está situada na localidade de Pedra Menina, distrito da municipalidade de Dores do Rio Preto (ES).

O PNC está relativamente próximo a grandes centros urbanos emissivos de turistas e desperta interesse dos visitantes por abrigar o Pico da Bandeira (2.890 metros de altitude), que até 1964 era considerado o ponto mais alto do Brasil e hoje se encontra em terceiro lugar, oferecendo excelentes vistas panorâmicas - e é o mais alto de Minas Gerais. Apesar da trilha ao Pico da Bandeira não apresentar vegetação exuberante e não possuir uma grande diversidade de fauna devido ao espaço ser um campo de altitude, a visita garante interesse ao valor paisagístico, e, além disso, a região do parque também é procurada por turistas de várias partes do Brasil que buscam por seus diversos cursos d'água, com corredeiras, cachoeiras e piscinas naturais, pelo verde dos vales e pelo relevo ideal para a prática de atividades de natureza em uma floresta tropical fluvial, que compõem todo o entorno do Parque Nacional do Caparaó circundado pela Mata Atlântica.

O Plano de Manejo (PM), que foi elaborado em 1979 e 1981, não possui portaria de acordo com informações da website do ICMBio, e trata de alguns objetivos como os quais: proteger as amostras de ecossistemas de "campo de altitude"; proteger amostras da floresta subcaducifólia tropical; proteger o Pico da Bandeira, área de interesse histórico-cultural nacional; proteger espécies da fauna, principalmente aves e mamíferos, raras, ameaçadas ou em perigo de extinção; proteger as nascentes dos rios que suprem a região; proporcionar ao visitante educação ambiental e interpretação dos diversos ambientes encontrados na área; possibilitar atividades de recreação e turismo, compatíveis com os demais objetivos de manejo; dentre outros. Como parte do plano, foram especificadas linhas gerais para o Programa de Uso Público, divididos em alguns subprogramas de manejo, que são: subprograma de recreação; subprograma de interpretação; subprograma de educação e subprograma de turismo. O PM recomenda que o número ideal de funcionários para atuar na unidade do PNC é de 184, porém, conta apenas com um total de 36 pessoas para a realização de todas as atividades administrativas e operacionais. Estes funcionários, em alguns anos atrás, já receberam diferentes tipos de formações, por meio de atividades ligadas ao Projeto Doces Matas (MORSELLO, 2000 ${ }^{1}$ apud KINKER, 2002), patrocinado por uma Agência Alemã de Cooperação Técnica, a GTZ.

Nesta pesquisa constatou-se que o atrativo mais visitado no Parque é o Pico da Bandeira e as nascentes de água protegidas pelo maciço do Caparaó. Dentre as principais atividades que os visitantes praticam se 
destaca a contemplação da natureza e das paisagens de altitude das montanhas, caminhadas, campismo, área para alimentação (churrasqueiras), e banhos em piscinas naturais e cachoeiras. O período de maior fluxo turístico na região é o de férias escolares, festas típicas da região e em finais de semana; para subir o Pico da Bandeira, a melhor época do ano é entre junho e agosto, pois a predominância de climas chuvosos é menor, além das baixas temperaturas serem mais favoráveis a escaladas e caminhadas nas montanhas. As áreas de acampamentos são bem acessadas por montanhistas e campistas. Entre o ano de 1997 e 1998 - Parque ganhou uma reforma nas estruturas de apoio ao turista, com a restauração de banheiros e telefones públicos, reforma nas guaritas de acesso, e a inauguração de uma portaria de acesso ao Parque pelo lado do Espírito Santo, que fica na localidade de Pedra Menina, município de Dores do Rio Preto (ES), e uma nova área de camping no local chamado Casa Queimada. A entrada ao Parque pelo lado do Espírito Santo foi resultado de um longo processo de discussões e reivindicações, pois os municípios localizados deste lado se sentiam prejudicados por não aproveitarem do desenvolvimento potencial que o fluxo turístico poderia oferecer, já na década de 90. A entrada no Parque é permitida entre 6 h30 e 22 horas diariamente. A estrada que segue ao Parque pelo lado capixaba impõe condições de tráfego limitadas, não sendo viável para ônibus e carros de passeio em época de chuvas, com isso, pode-se contratar o serviço de transporte em Jipes no distrito de Pedra Menina e região. O parque não possui alojamento para os visitantes; na entrada, são fornecidos folhetos explicativos sobre o parque, porém não há palestras programadas ou apresentações audiovisuais para enriquecer a visita do turista, assim como já era deficiente na época da pesquisa de Kinker (2002). Como uma Unidade de Conservação e de acordo com o estabelecido no Plano de Manejo, a realização ativa de Educação Ambiental é de suma importância para garantir as beneficies advindas da regulamentação das áreas protegidas.

O Instituto Chico Mendes de Conservação da Biodiversidade (ICMBio), em publicação em seu site $^{2}$, segue alguns dados em números sobre a visitação do PNC entre 2006 a 2010. Destaque em 2011, quando o Caparaó fica em 16ำ no ranking ${ }^{3}$ de visitações entre 26 parques nacionais.

Tabela 1: Visitantes PARNA Caparaó.

Table 1: Visitors PARNA Caparaó.

\begin{tabular}{|c|c|}
\hline Ano & Número de visitantes \\
\hline 2006 & 31.472 \\
\hline 2007 & 31.971 \\
\hline 2008 & 32.891 \\
\hline 2009 & 38.403 \\
\hline 2010 & 33.891 \\
\hline 2011 & 28.933 \\
\hline
\end{tabular}

Fonte: ICMBio (2013).

Source: ICMBio (2013). 
De acordo com a observação de Kinker (2002), em sua análise sobre o plano de manejo do PNC, a sinalização na UC indica apenas os locais e direções de usos permitidos na unidade, não há uma estrutura adequada para um efetivo programa de interpretação da natureza; dentre as trilhas, a subida ao Pico da Bandeira é a mais acessada, principalmente na época do inverno durante o dia ou a noite; ainda analisa que, o parque não busca explorar o seu potencial ecoturístico, deixando a desejar na sinalização e divulgação da área, fazendo com que a maioria dos turistas concentrem-se nos principais atrativos que são os de mais fácil acesso, ficando assim uma grande área do parque desconhecida e subutilizada. Há a possibilidade de se desenvolver outros tipos de roteiros em atividades de aventura no PNC, porém isto exige treinamentos específicos e formação de condutores aptos a segurarem as atividades. O serviço de condução no parque pode ser encontrado nas cidades que circundam 0 parque, com os próprios moradores da região, ou buscando informações junto aos funcionários do parque, pois não existe uma associação ou coordenação dos condutores, afirma Morsello (2000) em sua pesquisa utilizada por Kinker (2002). Porém a partir de 2013 por iniciativa do SEBRAE foram ofertados cursos de condutores ambientais e em 2014 cursos para formação de condutores de observadores de pássaros, despontando uma nova atividade para o seguimento ecoturístico da região do Caparaó que possui exuberante biodiversidade, e reafirmando a importância de se reavaliar o plano de uso público do Parque para criar bases legais para a utilização adequada de outras áreas dentro do Parque, de acordo com o devido manejo e proteção.

\section{Metodologia}

Como metodologia desta pesquisa foi-se adotado o campo da pesquisa baseada em história oral, que como classificado por Alberti (1989), é legítima como fonte de pesquisa porque não induz a mais erros do que outras fontes documentais e históricas. Isto porque, a história oral representa a ideologia em movimento, tendo a capacidade de "reconstituir", totalizar, reinterpretar um fato.

A pesquisa em história oral permite-se realizar uma análise qualitativa sobre o tema estudado, o que, no caso do turismo, surge como método muito valioso tendo em vista que parte das pesquisas estão voltadas para um resultado em números (quantitativo) da atividade turística. E a história oral permite analisar não somente um destino com base nos seus números de entradas assim como compreender o sistema social das relações que regem naquele espaço, sua aplicação e sua organização, em termos físicos (espaciais) e funcionais.

Como descrevem Bedim e Paula (2007, p.66):

Em nossa área de produção de conhecimento (Turismo), historicamente marcada pelas abordagens economicistas e quantitativas, é comum aqueles que os processos da pesquisa qualitativa - e nesta inclui-se a modalidade do método história oral - nutrirem a ideia de que ela pode ser realizada sem a presença de critérios metodológicos de 
pesquisa, como forma de controle de dados, validação de instrumento, aspectos éticos e legais, etc. Tudo isso talvez porque, aos olhos do observador desatento, não é tarefa científica sair por aí interpelando as pessoas com um gravador, um roteiro e algumas perguntas na cabeça. Faz-se importante, então, que tenhamos a reflexão necessária para compreender que tais instrumentos de investigação têm estatuto próprio, construído com base em décadas de prática de pesquisa, e para as quais temos que nos capacitar. Tendo em vista os processos sociais engendrados pelo turismo nas localidades receptoras, é possível que a história oral seja entendida como um instrumento potencial para registrar as mais variadas representações e anseios das "populações visitadas" [...]

Assim explica-se que a metodologia de história oral é sim valiosa, apesar de existirem aqueles que não dão credibilidade ao método, pensam que é realizada aleatoriamente e sem base científica para que seja comprovada e aceita. Esta metodologia é desenvolvida há anos e requer uma capacitação para realiza-la, e compreender que como proposto pelos autores, seja um instrumento potencial de analisar variadas representações.

A metodologia da história oral também possui a peculiaridade de escutar a voz de todos, de uma maneira totalizada e generalizada, até mesmo daqueles que por vezes estão considerados à margem de algum sistema, podem ser escutados e compreendidos, colaborando na construção do entendimento do fato. Assim, permite analisar os mais variados pontos de vista, de diferentes partes e com motivações também distintas, o que pode-se levar a compreensão de um todo interligado.

Assim, com esta característica generalizada, a história oral é constituída com a multidisciplinariedade em suas pesquisas e análises, o que é imprescindível para se obter resultados mais próximos da originalidade, que é analisar o objeto em sua totalidade, agregando diversas possibilidades, afim de se compreender o sistema, que no nosso caso, vem a ser como se dá a distribuição e organização do turismo em Patrimônio da Penha. "A descrição etnográfica apresenta como princípio a interpretação dos discursos sociais e a análise dos mesmos" (LAGE, 2009, p. 6).

As entrevistas ocorreram entre 28 e 30 de janeiro de 2013, em Patrimônio da Penha. Foram entrevistadas oito pessoas que residem na comunidade e de alguma forma estão envolvidas com o turismo, direta ou indiretamente relacionado ao turista.

Em um total de 3 horas 32 minutos e 07 segundos de entrevista gravados, para se obter os dados necessários aos fins da pesquisa, o roteiro de entrevista foi divido em três eixos principais que direcionaram a conversa, esses três eixos representavam o caminho para se obter as possíveis respostas para os problemas da pesquisa e do objeto de estudo. Estes três eixos muitas vezes se inter-relacionaram durante as entrevistas.

O primeiro eixo é composto por questões relacionadas ao entrevistado e suas informações pessoais, como por exemplo, nome, data e 
local de nascimento, por qual motivo se mudou pra Penha, ou se mantém na vila até os dias de hoje.

O segundo eixo diz respeito a memória do entrevistado para com a história da vila desde quando era criança, ou se mudou para Patrimônio da Penha, buscando-se saber sobre aspectos físicos e geográficos, comunitários, populacionais, organizacionais, e logicamente também abarcamos o tema turismo e sobre os turistas que começam a surgir nos últimos vinte anos aproximadamente.

O terceiro e último eixo finaliza indagando ao entrevistado sobre sua forma de envolvimento com o turismo, e procura saber de que forma ele está inserindo e trabalhando com o fenômeno turístico, há quanto tempo ele desenvolve esta atividade, suas opiniões e sugestões quanto a necessidades básicas e possíveis melhorias para a comunidade e o turista, assim como se de fato a comunidade está inserida com o turismo e em qual grau, e se é possível nos dias de hoje viver-se exclusivamente do turismo com o estabelecimento que possuem e gerenciam em Patrimônio da Penha.

Após coletados, as entrevistas foram devidamente transcritas, os dados foram categorizados e agrupados em temáticas específicas e submetidos à análise.

Os agentes entrevistados compreendem tanto os moradores nativos de Patrimônio da Penha quanto forasteiros que se mudaram e desde algum tempo vivem na vila, porém de comum acordo todos os entrevistados estão ligados de alguma forma à atividade turística, assim se caracterizam os entrevistados:

1 - Mulher, 35 anos, nativa, casada, proprietária de restaurante de comida caseira.

2 - Mulher, 45 anos, forasteira, casada, proprietária de um meio de hospedagem (pousada), reside em Patrimônio da Penha há 23 anos.

3 - Mulher, 43 anos, nativa, casada, proprietária de uma mercearia.

4 - Mulher, 31 anos, nativa, casada, sócia-proprietária de um restaurante.

5 - Homem, 45 anos, forasteiro, casado, proprietário de um albergue e camping, reside em Patrimônio da Penha há 23 anos.

6 - Mulher, 67 anos, forasteira, solteira, proprietária de um ateliê de tecelagem, reside em Patrimônio da Penha há 10 anos.

7 - Mulher, 43 anos, nativa, casada, proprietária de um restaurante e lanchonete.

8 - Mulher, 26 anos, filha de forasteiros, solteira, funcionária da secretaria municipal de Turismo de Divino de São Lourenço, município ao qual pertence o distrito de Patrimônio da Penha, reside no distrito há 23 anos, sendo criada em Patrimônio da Penha configura-se como nativa da região. 


\section{Testemunhos orais e considerações sobre a história do Turismo em Patrimônio da Penha: da tradição comunitária às possibilidades e dificuldades}

"O Caparaó tem várias fases, a primeira fase os índios que vieram pra cá na coisa de fugir dos brancos que chegavam pelos litorais principalmente pelo Espírito Santo, pelo norte do estado, teve o segundo movimento que foi o movimento madeireiro [...] depois tivemos a terceira fase que era a fase do café, quando a gente chegou aqui era a fase do café ainda, apesar de toda região do Caparaó, aqui em Patrimônio da Penha foi em menor proporção, movimento mais tímido, aqui a cultura do café nunca foi homogênea, e nós(forasteiros - hippies) somos essa quarta parte, que pode-se dizer a fase dos ambientalistas, que tem o eixo pra essa área do ecoturismo, o início do ecoturismo aqui."

(Proprietário de albergue, 45 anos)

Qual seria a maior preocupação do homem neste começo de século? Até quando vamos conseguir sobreviver sobre este planeta o qual o homem devastou, acelerou o seu processo natural de mudanças e agora sofremos com todas as questões ambientais? O aquecimento global, este calor excessivo dos dias atuais, a poluição descontrolada nos centros urbanos e a escassez de água em algumas partes do mundo. Ou seja, a região do Caparaó está privilegiada por ainda possuir um aspecto natural e com sua biodiversidade preservada. $E$ atualmente há uma tendência a valorização dos destinos de natureza quando muitos turistas buscam por um lugar que Ihe proporcione saúde e tranquilidade. A atividade turística na região do Caparaó (Figura 2) vem se desenvolvendo nos últimos anos e se mostrando como uma nova possibilidade no quadro econômico regional. Nota-se que o êxodo urbano vem aumentando quando algumas pessoas que foram turistas um dia decidem se mudar definitivamente, se instalam e buscam desenvolver suas vidas financeiras dentro das possibilidades locais, muitas vezes desenvolvendo atividade financeira dentro mesmo do setor turístico, outros já não podem se mudar definitivamente, e se enquadram como turistas flutuantes dessas áreas verdes preservadas continuando contribuindo com o movimento dos serviços turísticos do destino.

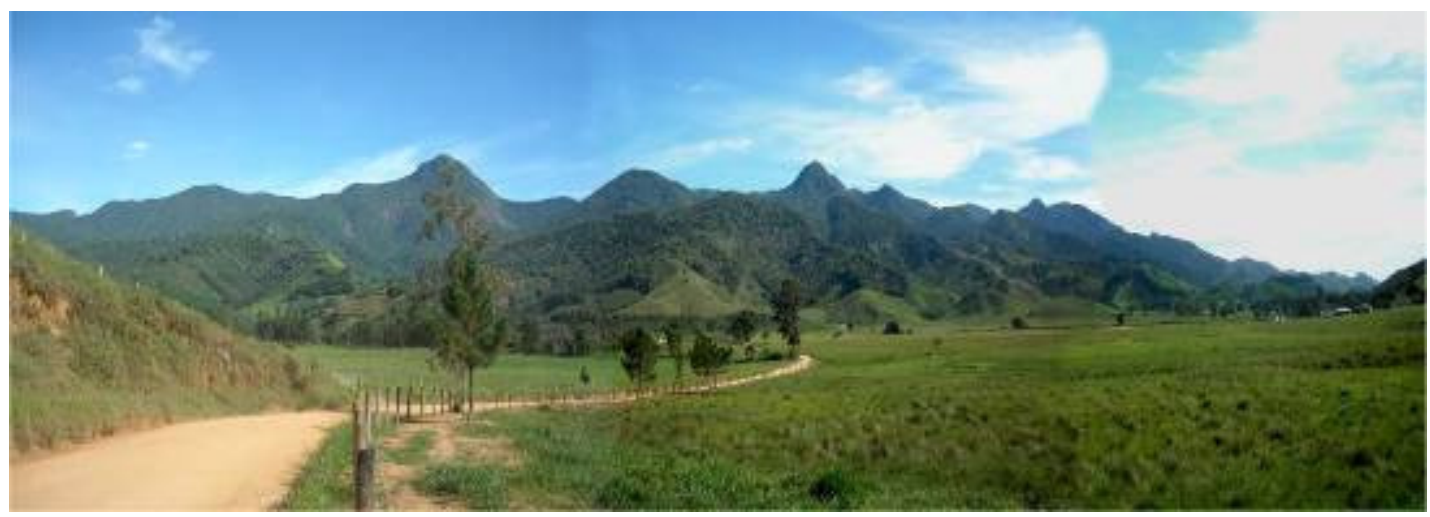

Figura 2: Cadeias de montanhas do Caparaó na chegada a Patrimônio da Penha.

Foto: Henrique Bretas, 2010.

Figure 2: Mountain ranges Caparaó on arrival at Heritage Penha.

Photo: Henry Bretas, 2010. 
De acordo com os estudos de Morsello (2000 apud Kinker, 2002), os serviços de hospedagem no entorno do PNC há algum anos atrás ainda eram escassos. No lado do Espírito Santo as hospedagens eram simples e pouco estruturadas, o tipo de acomodação mais comum é o denominado "cama e café", referindo-se a pensões ou acomodações em casas de famílias que veem no turismo uma atividade econômica paralela à produção agrícola, onde geralmente estes locais também servem refeições caseiras.

O que confirma-se no depoimento de uma moradora;

\begin{abstract}
Em 2000 veio o negócio do cama e café, que foi uma formação de pessoas da roça pra receber turistas, o turismo começou aqui com cama e café, foi um projeto do consórcio dos municípios do Caparaó, que veio com esse projeto, e eu já fui de cara assim uma das primeiras a fazer os primeiros cursos, ne, e começamos a receber, as pessoas começaram a receber dentro de casa e eu também comecei a receber dentro da minha casa (Proprietária de pousada, 45 anos).
\end{abstract}

Kinker (2002) notava há dez anos que empreendedores provenientes de outros municípios, estados e até mesmo países, vinham enxergando na região potencial de desenvolvimento turístico, e desde então realizando investimentos em equipamentos para atender estes turistas que começavam a surgir.

Conclui-se que a comunidade da Penha passou a ser conhecida e então houveram transformações dando início ao seu processo de turistificação a partir da década 1980, quando "forasteiros" de variadas origens chegaram a Patrimônio da Penha em busca de novos estilos de vida em contato com a natureza, buscando de alguma forma a integração física e espiritual. Nota-se a chegada de um perfil específico de morador, que relatam ter uma nova postura e preocupação ambiental adiante os problemas que o planeta já apresentava em decorrência de seu esgotamento para atender o desenvolvimento que cresce em maneira desproporcional aos recursos da terra. Estes seriam os ambientalistas que deram o ponta pé inicial na ideia de se desenvolver o ecoturismo na região, observando o potencial para isto. O que nota-se no mercado uma procura maior por parte dos turistas para os destinos e/ou pacotes que envolvem a natureza, e dentro deste segmento pode ser encontrado diversos tipos de serviços oferecidos ao turista abrangendo todas suas necessidades e expectativas em volta do tema principal que é o turismo de natureza.

Os motivos deste turismo são os mais diversos e atingem a parcela da população que busca por algo diferente, para uma simples exemplificação, podem-se ser comparados ao turista alocêntricos ${ }^{5}$, ou seja, aquele turista que é o primeiro e "desbravar" as novas terras, abrir o caminho de um lugar paradisíaco e até então inexplorado pelo forasteiro, e sim só pelo morador autóctone, assim como os novos moradores da região do Caparaó que chegaram a partir da década de 1980, citados anteriormente. Este foi um movimento que teve sua gênese na década de 1970 no Brasil e estes turistas são categorizados como alocêntricos por 
PLOG $\left(1973^{6}\right.$ apud FERREIRA REZENDE; CARVALHO DE REZENDE, 2008). Segundo este autor o grupo dos alocêntricos são os turistas que buscam por novos destinos e podem facilmente adaptarem-se aos costumes locais, geralmente tem maior poder aquisitivo.

Notou-se que, os que ali se instalavam para viver foram procurando formas de se manterem economicamente, muitos foram trabalhar na cafeicultura e na construção civil, e alguns começavam a se dedicar à atividade turística, trabalhando com artesanatos ou se preparando para receber os turistas que viajando iam chegando nas serras do Caparaó. Porém, o ritmo de crescimento e desenvolvimento em Patrimônio da Penha se dá em um processo gradativo, resultando que até hoje o turismo ainda é uma atividade não muito bem compreendida pela população; "tem muita gente que não entende, e nem sabe o que é o turismo, às vezes o pessoal aqui da comunidade deixa vir uma pessoa lá de fora pra trabalhar ao invés de eles correr atrás." (Proprietária de restaurante, 43 anos).

A partir de um evento, O ENCA (Encontro de Comunidades Alternativas - 1991), que foi um marco na história do turismo da Penha, que atraíra um público quanto diferente e inusitado, que seria a geração dos hippies, momento este que é percursor do turismo em Patrimônio da Penha, não é só quando se atentam para um novo paraíso, mas também quanto para a designação de um segmento a ser trabalhado por espontaneidade local, o turismo místico, que com o passar dos anos veio sendo cada vez mais explorado. O turismo místico ou esotérico é uma questão específica que caracteriza um segmento que caminha junto com a busca pelo turismo no meio ambiente, onde o turista busca a interiorização e 0 autoconhecimento através de um contato mais profundo com a natureza e a essência do ser.

Fator este que se perdurou nos últimos anos consolidando uma base segura de que este sim é um segmento forte no distrito, atraindo no ano de 2012 mais evento de grande porte com o mesmo propósito ambientalista e de reaproximação do homem à terra: o RAINBOW. O encontro internacional de comunidades alternativas aconteceu entre janeiro e fevereiro de 2012 no Vale da Jacutinga, vizinho de Patrimônio da Penha, na mesma cadeia de montanhas que amortecem e limitam o Parque Nacional do Caparaó. Este evento atraiu cerca de 2.000 pessoas no seu ápice de público, que se dá na Lua cheia, geralmente no meio do evento que dura um mês (um ciclo completo lunar).

Centenas de pessoas da chamada Rainbow Family se reúnem todos os anos em alguma parte do planeta para viver dias de utopia: o Rainbow Gathering [encontro do arcoíris] é um festival que já tem mais de 38 anos, e a cada edição reúne centenas de pessoas, em acampamentos ao ar livre para celebrar e praticar ideais de paz, amor, harmonia, liberdade e comunidade, como uma alternativa ao consumismo, capitalismo e costumes vigentes. A Trip recentemente foi a um desses encontros, no Espírito Santo, e contou como eles se preparam para a era de luz que, acreditam, está por vir (Revista Trip) ${ }^{7}$. 

de 2014.

Uma nova edição do ENCA no Caparaó voltou a acontecer em julho

Devido ao fator de que os atrativos da Penha estarem ligados ao meio ambiente, a natureza, como as águas das cachoeiras, a vila possui um fluxo maior de turistas nas épocas de janeiro e fevereiro, que correspondem ao verão. Juntamente também se considera dezembro e março meses de alta temporada no distrito; "é no verão agora né, de dezembro a fevereiro, março também" (Proprietária de restaurante, 31 anos).

E ainda o fator de a vila ser localizada em uma região de altitude, montanhas cobertas por mata atlântica, o inverno é rigoroso e atrai uma demanda turística que busca pelas noites frias da região das montanhas, ressaltando-se os meses de junho e julho pelos entrevistados. No geral, destacam os períodos das férias escolares como favoráveis ao aumento no fluxo turístico regional; "junho e julho, nas férias né, sempre é nas férias" (Proprietária de restaurante, 43 anos).

A principal motivação por parte dos turistas que visitam conhecer Patrimônio da Penha é pelo desejo de estar próximos às suas belezas naturais, caracterizando assim o meio ambiente o principal atrativo da região, onde as pessoas podem ter contato com as águas puras das cachoeiras, desfrutar do clima agradável da montanha, do ar puro, a floresta, a tranquilidade do local e o Parque Nacional do Caparaó. Como destacado no depoimento de duas das entrevistadas:

Primeiro o Parque Nacional do Caparaó e as belezas naturais que tem aqui, as cachoeiras, e além disso a questão do misticismo também que traz muito, a questão do Santo Daime, a lenda da comunidade alternativa, que todo mundo acha que aqui ainda tem a comunidade alternativa (Funcionária da prefeitura, 26 anos).

Em Patrimônio da Penha em particular é o turismo de cura, assim, turismo de saúde. Então como aqui moram muitos terapeutas, muitos vegetarianos, então aqui também criou esse marketing de ser um lugar de cura, de saúde, onde a pessoa vai encontrar um massoterapeuta, um reikiano, vai encontrar uma pessoa que faz uma homeopatia, uma medicina mais alternativa, então a gente também recebe muitas pessoas nessa área do turismo de saúde (Proprietária de pousada, 45 anos).

Assim, há constantemente uma percepção do aumento do fluxo turístico, como notado em diversos depoimentos recolhidos em campo, nos quais os proprietários de empreendimentos voltados ao turista garantem que o número de visitantes tem crescido de ano em ano, e com isso novos empreendimentos também vão surgindo para atender as necessidades dos visitantes, em diversas áreas como por exemplo hotelaria e alimentação. 


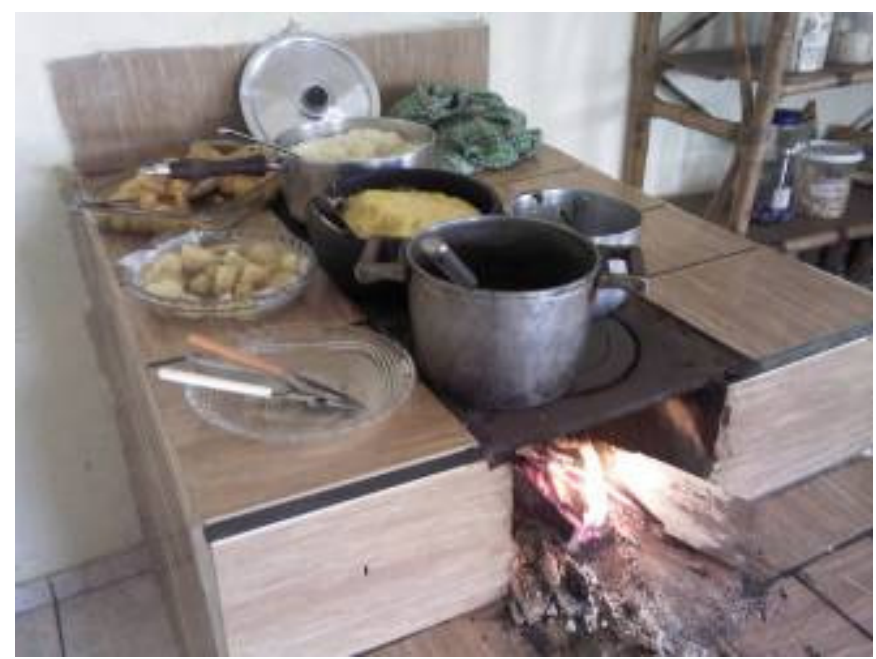

Figura 3: Interior do restaurante em Patrimônio da Penha. Fonte: Autor da pesquisa, 2013. Figure 3: Interior of restaurant Patrimônio da Penha. Source: Author's survey, 2013.

As comunidades que circundam toda a área do PNC são influenciadas e influentes nas condições de preservação e concepção desses espaços naturais. Estas comunidades contam como uma das principais atividades econômicas na região atualmente a cafeicultura e a agropecuária. Há oportunidades de inserção ocupacional na agricultura familiar, já que os agricultores trabalham por conta própria, e por muitas vezes com sua família, seja como parceiros, ou na sua própria terra. Porém observou-se, em campo, que as oportunidades de ocupação para os jovens encontram-se limitadas, restando-lhes trabalhar na terra com a família, ou na construção civil, que atualmente são as duas opções mais viáveis. $O$ artesanato é uma atividade que poderia ser mais apoiada e desenvolvida se as pessoas que produzem recebessem algum tipo de apoio à comercialização, o que poderia ser alcançado a partir do cooperativismo.

Patrimônio da Penha possui muitos residentes que são artesãos, que expressam a cultura popular regional através de seus trabalhos, e por fim tentam escoá-los até o consumidor final (turista). Para este fim, realizam-se feiras no centro da comunidade todos os sábados pela manhã assim como outros eventos, também ocorrem atividades para a comunidade e interessados como: oficinas de manejo de bambu; rodas de capoeira; shows musicais; ensaios e apresentações do Circo Teatro Capixaba entre outras manifestações culturais que possam surgir na comunidade.

Ao mesmo instante em que se preocupa com a vinda do turista e visitante para conhecer a região e consumir a produção local, existe certa consciência com a chegada de muitas pessoas na vila e a massificação do turismo, e observa-se outras localidades que, como Patrimônio da Penha, eram procurados por suas características de paz e tranquilidade e hoje já se encontram alterados pois perderam aquele principal diferencial e atrativo do destino.

Contudo, para que se aumente o fluxo turístico na região é necessário "organização e divulgação" e o turismo ainda não é visto como uma atividade que, quando organizado, pode atuar de maneira progressista, os negócios todavia são de uma maneira bem particular e amadora deixando a 
desejar para alguns turistas que eventualmente esperavam infraestrutura e serviço qualificado. Falta ainda o pleno interesse do poder público para a realização de um planejamento efetivo que tenha como objetivo desenvolver a atividade turística de maneira consciente na região, assim juntamente com demais organizações oferecendo condições favoráveis ao surgimento e durabilidade de empreendimentos privados.

Os moradores entrevistados também relataram alguns problemas que a vila ainda enfrenta e que gostariam que fossem selecionados para que menos problemas lhes fossem ocasionados, questões como a saúde, a segurança pública, serviços de comunicação e transporte entre outros foram apontados pelos entrevistados.

No ano de 2011, com a preocupação de se planejar estrategicamente a atividade turística na região, a Secretaria Estadual de Turismo do Espírito Santo realizou reuniões entre as partes interessadas no distrito para definir metas de manejo da atividade turística na região e propor melhorias na utilização dos recursos hídricos, garantindo sua sustentabilidade. Apesar de existirem pousadas e restaurantes para atender aos turistas, ainda há problemas quanto à acessibilidade ao local devido aos restritos horários de transporte público para chegar ou sair da Penha, que vem sendo diminuída com a implementação em 2012, do asfalto nas estradas que dão acesso à Patrimônio da Penha, por Dores do Rio Preto a obra já está concluída, e no acesso por Divino de São Lourenço já chegam à fase final, e é um tema que recentemente gerou um conflito na vila, a questão do asfalto que passa pela vila de Patrimônio da Penha pelos seguintes motivos constatados na pesquisa. $O$ relato de uma forasteira a respeito do asfalto explica qual seria o motivo do desgosto por parte dos nativos para com os forasteiros, que tinham interesses divergentes em relação ao asfalto; No projeto o asfalto passaria dentro da vila, e por fim isto ocorreu, apesar de ter havido assembleias e discussões para expor as opiniões de ambos os lados, e os motivos dos forasteiros para não quererem o asfalto ali dentro, os nativos conseguiram que a sua vontade prevalecesse. A vontade dos forasteiros era realizar um desvio de alguns quilômetros para que o asfalto não passasse diretamente dentro da vila, pelo motivo de que seguramente a tranquilidade do local estaria ameaçada, e foi o que de fato se pode observar em campo, muitos caminhões já transitam dentro da vila dia e noite, e um fator agravante constatado é que a Penha está localizada em uma região de "brejo" e devido a isso seu terreno é muito instável, pode-se dizer "macio", afunda facilmente e isto pode ser observado que com pouco tempo que os caminhões transitam por ali e já se nota muitos buracos no caminho, além desse caminho transitado por carros e caminhões ser uma ameaça para as crianças da localidade que estavam habituadas a brincar na rua como é comum nas regiões interioranas.

A seguir o depoimento de uma moradora forasteira sobre a questão do asfalto, e uma imagem do asfalto na entrada da vila.

Eles (nativos) queriam muito a estrada, os "malucos"
(forasteiros) é que não queriam a estrada, saiu como era pra
sair mesmo, só que houve uma luta pela moçada de fora de
barrar a estrada, mas não era de barrar a estrada, era de
que se fizesse um desvio em que ela passasse pelo lado de 
fora da vila de $P$. da Penha, mas foi uma conversação que durou muito tempo, mais de ano, e nunca eles (nativos) entenderam o que as pessoas queriam, o que as pessoas de fora queriam, era mais os de fora mesmo que queriam, nós não queríamos barrar a estrada, a estrada a gente também necessita dela, a gente só queria que ela desviasse da Penha, mas esse pequeno desvio, pra eles era assim um ante progresso. Pensavam que o progresso viria com a estrada passando aqui dentro. Pensavam que iam ficar isolados, e com essa falta de entendimento entre as pessoas de fora e as pessoas daqui houve um racha, e a partir dessa história de estrada que durou anos, e hoje a população é dividida entre os de fora, e os nativos, coisa que não existia, a gente estava totalmente ligado, e era boi pintadinho, na igreja da vila a gente ia, tudo, até hoje sim ainda tem todo mundo ta se relacionando mas antigamente era muito mais, foi uma divergência de ideias que deu um racha (Proprietária de pousada, 45 anos).

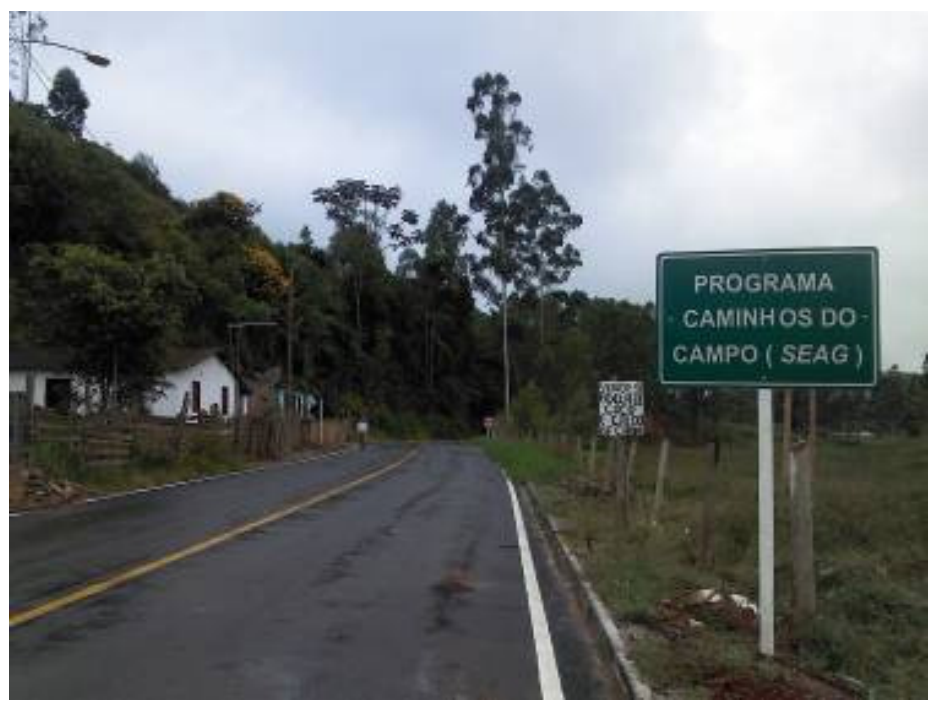

Figura 4: Estrada que contorna o Parque Nacional do Caparaó - ao lado do Espírito Santo. Fonte: Autor da pesquisa, 2013.

Figure 4: Road bordering the National Park Caparaó - side of the Espírito Santo. Source: Author's survey, 2013.

De acordo com um trabalho desenvolvido pelo Pró-Città (INSTITUTO DE ESTUDOS PRÓ CIDADANIA ${ }^{8}$ apud KINKER, 2002), o a população em Patrimônio da Penha em 1996 era de 258 habitantes. Desde 1996 até hoje a população cresceu consideravelmente, como relatado pelo olhar de uma entrevistada, 26 anos, que acredita que atualmente a população gira em torno de "aproximadamente 400" habitantes. Uma entrevistada, 67 anos, aponta uma questão importante que é que, além do aumento populacional considerado normal, ainda há uma considerável evasão, principalmente dos jovens que deixam a vila em busca de emprego nas cidades maiores da região, abandonando a vila da Penha; "porque também há uma evasão grande, principalmente dos jovens, quando eu mudei pra cá tinha 300 habitantes, eu tenho a impressão que agora está em torno de 350, 400 habitantes". 
De fato essa evasão ocorre frequentemente, uma das entrevistadas relata a saída de três filhos da Penha em busca de condições melhores fora dali, já que não há muitas opções ocupacionais.

O desenvolvimento da atividade turística pode ser - e aos poucos a comunidade passa a ter essa visão - uma ajuda no orçamento mensal da família e que se fosse mais bem planejado e desenvolvido, conseguisse suprir em uma parte a falta de empregabilidade na região diminuindo a evasão populacional.

Nota-se que com a facilidade à chegada de produtos na vila da Penha empresas de construção civil se instalaram na região e podem oferecer preços irresistíveis para as pessoas do interior, que visando a economia financeira optam por materiais não condizentes com a arquitetura tradicional local, o que gera uma desconfiguração do padrão e além disso muitas vezes interferindo negativamente no meio ambiente, tendo em conta que até o momento não foi aprovado pelo governo um plano de uso e ocupação do solo, tampouco a regularização de uma forma de fiscalizar a preservação do patrimônio tanto arquitetônico como natural da região. Hoje a Penha possui uma única casa tombada recentemente, como Patrimônio Histórico do município de Divino de São Lourenço, a casa foi comprada para se transformar em um supermercado e algumas pessoas engajadas na comunidade impediram que ela fosse desestruturada, conseguindo assim manter sua forma original e o tombamento como garantia de preservação.

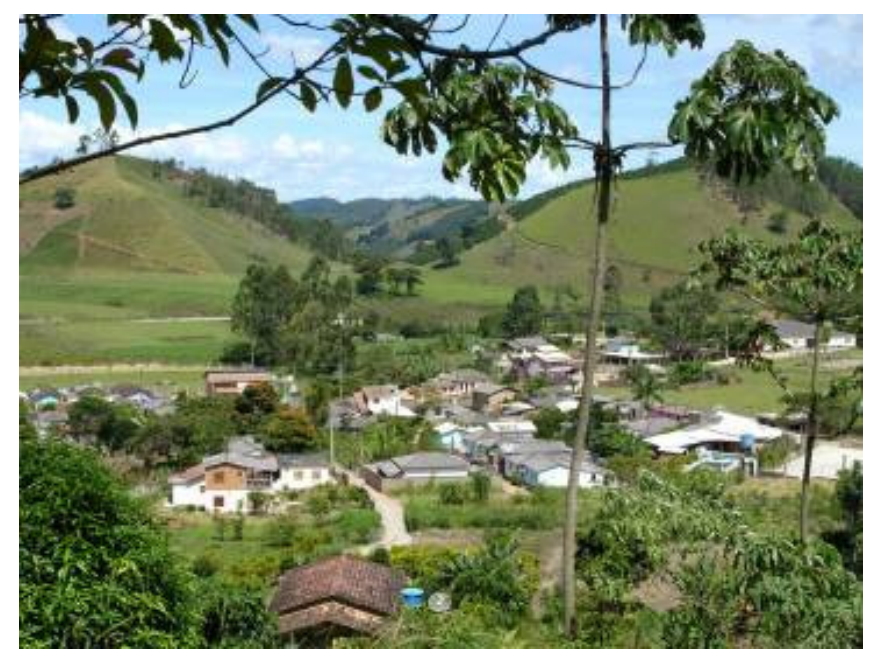

Figura 5: Desenvolvimento da comunidade de Patrimônio da Penha.

Fonte: Autor da pesquisa, 2013.

Figure 5: Development community of Heritage Penha. Source: Author's survey, 2013.

O turismo que é desenvolvido em áreas naturais frágeis como o cenário no qual está inserido Patrimônio da Penha, precisa ser planejado e desenvolvido de maneira preservacionista, original e também inovadora, pois o meio ambiente e a cultura local são os conteúdos que os turistas procuram e precisam encontrar, portanto, se não há meio ambiente preservado não há ecoturista, e pode-se pensar também ao contrário, pois o ecoturista é um grande responsável e aliado a preservação do meio ambiente. Assim buscou-se ter conhecimento das medidas tomadas pelo governo pensando 
no controle do uso e preservação também do meio ambiente quando se pensa em ecoturismo. Pensa-se regionalmente a respeito de uma possível guarda ambiental para atuar especificamente na fiscalização e controle dos bens naturais do entorno do Parque Nacional do Caparaó, de acordo com as diretrizes e normas voltadas para regularização do uso público destas áreas.

"Por extensão, pode-se esperar que o nível de poluição das águas, do solo e da paisagem total também venham a ser um fator (...) decisivo para a escolha dos destinos turísticos" (MOLINA, 2001, p.61).

Portanto, é fato a riqueza econômica que pode gerar todo este meio bem preservado, pois hoje em dia já foi observado que às vezes o morador local pode ganhar muito mais se ele mantém uma natureza intacta em um espaço, por exemplo, que se resolvesse exterminá-la. A natureza é a principal riqueza e pode ser a fonte principal da economia através do turismo, porém, se bem trabalhado, dando oportunidades as pessoas locais, para que eles desenvolvam o seu espaço e se desenvolvam pessoalmente também com aspectos positivos.

\section{Considerações Finais}

A proximidade do distrito de Patrimônio da Penha em relação ao Parque Nacional do Caparaó é um dos atributos que confere à região grande interesse turístico, quando muitas pessoas que estão na busca do contato com a natureza preservada passam pela localidade e consequentemente movimentam um ciclo de atividades turísticas na região. Isso engendra a cadeia produtiva local, haja vista a necessidade de produtos e serviços para atenderem aos turistas.

Em campo pôde-se obter informações dos entrevistados acerca do turismo no Parque Nacional do Caparaó, enquanto influência do fluxo turístico para o distrito de Patrimônio da Penha, que, como visto, situa-se em seu entorno.

Abaixo uma tabela com os principais marcos na cronologia do desenvolvimento turístico na Penha constatado na pesquisa:

Tabela 2: Cronologia do Desenvolvimento Turístico na Penha.

Table 2: Chronology of Tourism Development in Penha.

\begin{tabular}{|c|c|}
\hline Ano & Ocorrência \\
\hline 1961 & Criação do Parque Nacional do Caparaó \\
\hline 1989 & Chegada dos primeiros forasteiros \\
\hline 1991 & Encontro de comunidades alternativas (600 visitantes) \\
\hline 2000 & Projeto Cama e Café do governo do estado do Espírito Santo \\
\hline 2007 & MoVa Caparaó - Mostra Capixaba Audiovisual Ambiental \\
\hline 2012 & Rainbow Gathering / Inauguração do asfalto (estrada parque) na vila \\
\hline
\end{tabular}

Fonte: Autor da pesquisa, 2013.

Source: Author's survey, 2013. 
Praticamente todos os entrevistados acreditam que a localidade da Penha recebe um fluxo turístico que é devido a existência do Parque Nacional. A vinda dos forasteiros para estas terras se encontram baseadas justamente no fato da existência do Parque, o que se pode considerar que tinham a consciência que com a existência de uma unidade de conservação na região iriam aumentar as atuações em prol da preservação da natureza e assim crescendo o movimento ambientalista na região.

[...] porque se você for pensar esse pessoal que veio pra montar a comunidade alternativa só veio por causa do Parque, e depois ficou famoso por causa dele (Parque), em função das belezas naturais, e quem em acaba desfrutando das cachoeiras e de todos outros atrativos naturais, e a beleza cênica (Funcionária da prefeitura, 26 anos).

Nesta pesquisa notou-se que o PARNA Caparaó é considerado pelos empreendedores da região como "o carro chefe" do turismo. "Muitos perguntam de lá (Parque), muitos tem a curiosidade de conhecer, aí junta tudo, que as cachoeiras já ficam tudo dentro do Parque" (Dona de restaurante, 35 anos).

Os empreendimentos aproveitam a fama do Parque Nacional Caparaó, e principalmente aliado ao seu principal atrativo, o Pico da Bandeira. Porém o quesito uso público do plano de manejo do Parque ainda não está estruturado de acordo com o desenvolvimento da atividade turística no interior da UC, esta que tem forte poder atrativo de turistas que consequentemente visitam e movimentam a região do entorno e suas comunidades, porém dentro do Parque, as únicas trilhas permitidas para o turismo são as que levam ao Pico da Bandeira.

Os programas de preparação e capacitação para o desenvolvimento da atividade turística na região já estão conscientes e alertam os investidores que, tendo esta realidade do uso público restrito das áreas do Parque, e o grau de dificuldade no acesso deste principal atrativo oferecido - o Pico da Bandeira, é necessário trabalhar na preparação e divulgação de outras opções para o ecoturista, que as vezes procura a tranquilidade de um destino de natureza porém as atividades de aventura que exigem muitos esforços não é o que lhe chama mais a atenção, podendo outros seguimentos serem trabalhados como o turismo gastronômico, o turismo de observação de aves, por exemplo, e que estas atividades sejam desenvolvidas principalmente em toda a região do entorno do Parque Nacional do Caparaó.

Com o advento da atividade turística na região e a chegada de novos moradores, novos proprietários das áreas rurais, muitas lavouras de café já deram espaço para as matas voltarem a crescer, fator que beneficia 0 ecoturismo pautado na experiência do visitante e o contato direto com a natureza, isto pode ser começa-se a ser observado nas margens do distrito de Patrimônio da Penha. Assim, segue se alterando a cultura tradicional, na qual era comum o trabalho nas lavouras do café, com a inserção da atividade ecoturística a qual zela pela preservação de sua matéria prima que é o meio ambiente.

Com este trabalho pode-se observar que o Parque Nacional exerce determinada influência na reestruturação da esfera produtiva da comunidade analisada, à medida que as demandas turísticas engendram o surgimento de 
serviços e empreendimentos locais voltados para atender ao turista que por vezes passa por aquela localidade indo até o atrativo ou até mesmo se hospeda ali e usufrui dos demais serviços - agregando assim à economia local. Em Patrimônio da Penha, o turismo é tido como um terceiro alicerce econômico, a saber: pecuária, construção civil e ecoturismo.

As comunidades que circundam toda a área do Parque Nacional do Caparaó são influenciadas e influentes nas condições de preservação e concepção desses territórios. Estas comunidades contam a cafeicultura e a agropecuária, sendo as principais atividades econômicas na região atualmente. Há oportunidades de inserção ocupacional na agricultura familiar, já que os agricultores trabalham por conta própria, e por muitas vezes com suas famílias, seja como parceiros ou na sua própria terra. Porém observa-se que as oportunidades de ocupação para os jovens encontram-se limitadas, restando-Ihes trabalhar na terra com a família ou na construção civil, que atualmente constituem as duas opções mais viáveis. O artesanato é uma atividade que poderia ser mais apoiada e desenvolvida se as pessoas que produzem recebessem algum tipo de apoio à comercialização, o que poderia ser alcançado a partir do cooperativismo. Um fator importante a se ressaltar é que, muitas vezes quando surge uma nova vaga para se atuar no setor da construção civil, por exemplo, este emprego pode ter sido gerado indiretamente a partir da atividade turística, quando surge a necessidade de construir novos espaços ou intervir em outros já existentes os apropriando de maneira mais condizente com a atual proposta.

Enquanto influência do fluxo turístico para o distrito de Patrimônio da Penha, todos os proprietários de empreendimentos da localidade de que foram entrevistados em pesquisa, em janeiro de 2013, afirmam que o Parque Nacional do Caparaó hoje é o principal atrativo turístico da região, recebendo um notável fluxo turístico devido a existência do Parque, atrai sempre mais e mais pessoas para conhecer as comunidades do entorno, e cada uma com sua peculiaridade, atende o turista quase que de forma personalizada, característica intrínseca neste tipo de turismo exercido em zonas rurais, quando o processo ainda se desenvolve em pequena escala, pode-se oferecer um atendimento diferenciado à cada turista. Uma entrevistada em uma pesquisa chega a ressaltar que, a vinda dos forasteiros para estas terras (Patrimônio da Penha) se encontram baseadas justamente no fato da existência do Parque, o que se pode considerar que tinham a consciência que com a criação de um Parque na região iriam aumentar as atuações em prol da conservação natureza e assim também ia crescendo o movimento ambientalista na região.

Os parques nacionais podem e devem ser polos que auxiliem 0 desenvolvimento da região, mas para isso é preciso que haja planejamento, e este seja participativo e integrado entre todo o circuito. Segundo os entrevistados compreende-se que veem o parque como um meio de trazer benefícios para a comunidade através do turismo e da conservação do meio ambiente.

Sabendo-se que qualquer tipo de intervenção a partir do turismo gera impactos negativos e positivos, é necessário realizar planejamentos e os impactos devem ser monitorados continuamente para evitar efeitos negativos na comunidade ou pelo menos tentar minimiza-los. 


\section{Referências Bibliográficas}

ALBERTI, V. História oral: a experiência do CPDOC. Rio de Janeiro, RJ: Editora da Fundação Getúlio Vargas, 1990.

BEDIM, B.P. O processo de intervenção social do turismo na Serra de Ibitipoca (MG): simultâneo e desigual, dilema camponês no paraíso do capital. Belo Horizonte: Instituto de Geociências/Universidade Federal de Minas Gerais, 2008. (Dissertação de Mestrado)

BEDIM, B.P.; PAULA, H.E. "Relatos Visitados": História oral e pesquisa em turismo e hospitalidades. Considerações teórico-metodológicas. Caderno Virtual de Turismo, Rio de Janeiro, v. 7, n. 1, p. 63-77, 2007.

BRASIL. Lei no 9.985, de 18 de julho de 2000. Regulamenta o art. 225, $1^{\circ} \S$, incisos I, II, III e VII da Constituição Federal, institui o Sistema Nacional de Unidades de Conservação e dá outras providências. Disponível em: $<$ http://www.planalto.gov.br/ccivil 03/leis/L9985.htm>. Acesso em 04 Set. 2011.

CLAVAL, P. "A volta do cultural" na Geografia. Mercator. Revista de Geografia da UFC, n. 01, 2002.

ELIAS, N.; SCOTSON, J.L. Os estabelecidos e os outsiders: sociologia das relações de poder a partir de uma pequena comunidade. Tradução de Vera Ribeiro. Rio de Janeiro: Jorge Zahar, 2000.

Decreto federal ํㅜ 50.646, 1961.

$<$ http://www.icmbio.gov.br/portal/images/stories/imgs-unidadescoservacao/caparao.pdf> Acesso em 20 de set. de 2014.

DIEGUES, A.C. As áreas naturais protegidas, o turismo e as populações tradicionais. In: SERRANO, C.M.T.; BRUHNS, H.T. (Orgs.) Viagens à natureza. Turismo, cultura e ambiente. Campinas: Papirus, 1997. p. 85-102.

EAGLES, P.F.J.; MCCOOL, S.F.; HAYNES, C.D. Sustainable tourism in protected areas. Guidelines for planning and management. Gland: IUCN (International Union for the Conservation Nature), 2002.

KINKER, S. Ecoturismo e Conservação da natureza em parques nacionais. Campinas, SP: Papirus, 2002.

LAGE, G. Revisitando o método etnográfico: contribuições para a narrativa antropológica. Rio de Janeiro, RJ: Revista Espaço Acadêmico, no 97, 2009. $<$ http://periodicos.uem.br/ojs/index.php/EspacoAcademico/index> Acesso em 15 de abr. de 2013.

MOLINA, S.E. Turismo e Ecologia. Tradução Josely Vianna Baptista. Bauru, SP: EDUSC, 2001.

MORSELLO, C. Programa de uso público do Parque Nacional do Caparaó. Brasília: Ibama, 2000.

NEIL, J.; WEARING, S. Ecoturismo: impactos, potencialidades e possibilidades. Barueri, SP: Manole, 2001.

Plano de Manejo do Parque Nacional do Caparaó, 1979.

$<$ http://www.icmbio.gov.br/portal/biodiversidade/unidades-de-

conservacao/biomas-brasileiros/mata-atlantica/unidades-de-conservacao-mataatlantica/2202-parna-do-caparao > Acesso em 22 de set. de 2014. 


\section{Notas:}

1 MORSELLO, C. "Programa de uso público do Parque Nacional do Caparaó". Brasília: Ibama, 2000.

2 http://www.icmbio.gov.br/portal/comunicacao/noticias/20-geral5/3280-dos-69parques-nacionais-26-estao-oficialmente-abertos-ao-turismo.html. $<<$ Acesso em 17/03/2013>>

${ }^{3}$ http://www.icmbio.gov.br/portal/images/parques\%20ranking.pdf. $<<$ Acesso em $17 / 03 / 2013>>$

${ }^{4}$ MORSELLO, C. "Programa de uso público do Parque Nacional do Caparaó". Brasília: Ibama, 2000.

${ }^{5}$ No outro lado haveriam os psicocêntricos, que seriam que seriam os turistas que optam por atrativos mais populares - menos exclusivos.

${ }^{6}$ PLOG, Why destinations áreas rise and fall in popularity. Nova York: Cornell H.R.A Quarterly, 1973.

${ }^{7}$ http://revistatrip.uol.com.br/so-no-site/rainbow-gathering.html. $<<$ Acesso em 06/03/2013>>

8 PRÓ-CITTÀ. "Projeto 'Doces Matas' - PN 93.2538 .2 - 01.100 - Perfil socioeconômico das comunidades do entorno do Parque Nacional do Caparaó", vol. I. Resumo Executivo. Belo Horizonte, 1997.

Victor Silveira Massini: Universidade Federal de Ouro Preto, Ouro Preto, MG, Brasil.

E-mail: massini.ufop@gmail.com

Link para o currículo Lattes: http://lattes.cnpq.br/5488257984423892

Bruno Pereira Bedim: Universidade Federal de Ouro Preto, Ouro Preto, MG, Brasil.

E-mail: brunobedim@yahoo.com.br

Link para o currículo Lattes: http://lattes.cnpq.br/1654772916093941

Ricardo Eustáquio Fonseca-Filho: Universidade Federal de Ouro Preto, Ouro Preto, MG, MG, Brasil.

E-mail: ricardo@degeo.ufop.br

Link para o currículo Lattes: http://lattes.cnpq.br/1600424426811223

Data de submissão: 01 de julho de 2013

Data de recebimento de correções: 08 de outubro de 2014

Data do aceite: 08 de outubro de 2014

Avaliado anonimamente 